\title{
Corrigendum
}

\section{Corrigendum to "How Households Adopt Sustainable Innovations? A Free Decision Enforced by Others"}

\author{
Ingo Kastner (iD) and Sebastian Bobeth \\ Otto-von-Guericke University Magdeburg, Institute of Psychology, Department of Environmental Psychology, \\ Universitätsplatz 2 Magdeburg 39106, Germany
}

Correspondence should be addressed to Ingo Kastner; ingo.kastner@ovgu.de

Received 30 September 2018; Accepted 2 October 2018; Published 1 November 2018

Copyright (C) 2018 Ingo Kastner and Sebastian Bobeth. This is an open access article distributed under the Creative Commons Attribution License, which permits unrestricted use, distribution, and reproduction in any medium, provided the original work is properly cited.

In the article titled "How Households Adopt Sustainable Innovations? A Free Decision Enforced by Others" [1], there were errors in Figure 5. The confidence intervals of technical interest were missing and there was an error in the description of the figure. The corrected figure along with the description is shown below.

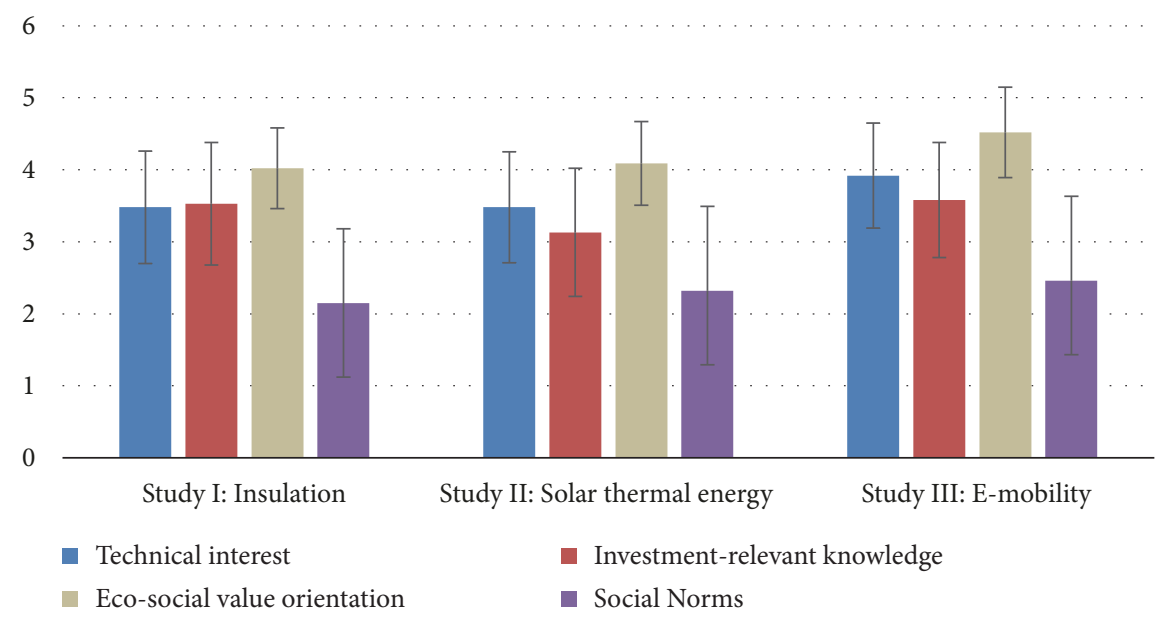

FIGURE 5: Descriptive data (means and standard deviations) of the independent variables and scales measured within the studies. Most items were measured on a 5-point Likert scale. In studies I and II, investment-relevant knowledge was measured on a 6-point Likert scale. The items were standardized for further analyses.

\section{References}

[1] I. Kastner and S. Bobeth, "How households adopt sustainable innovations? A free decision enforced by others," Journal of Energy, vol. 2018, Article ID 8960372, 11 pages, 2018. 

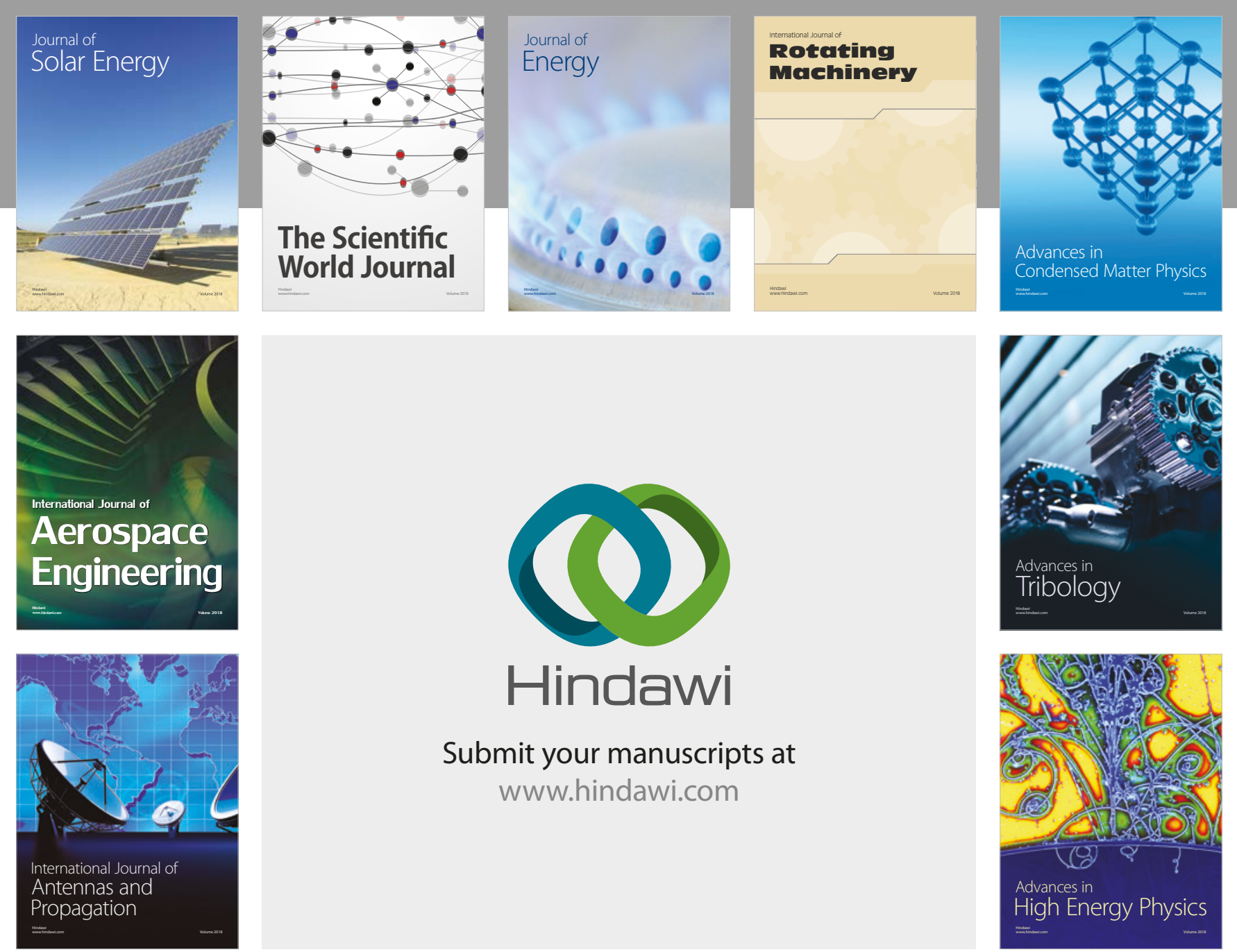

Submit your manuscripts at

www.hindawi.com
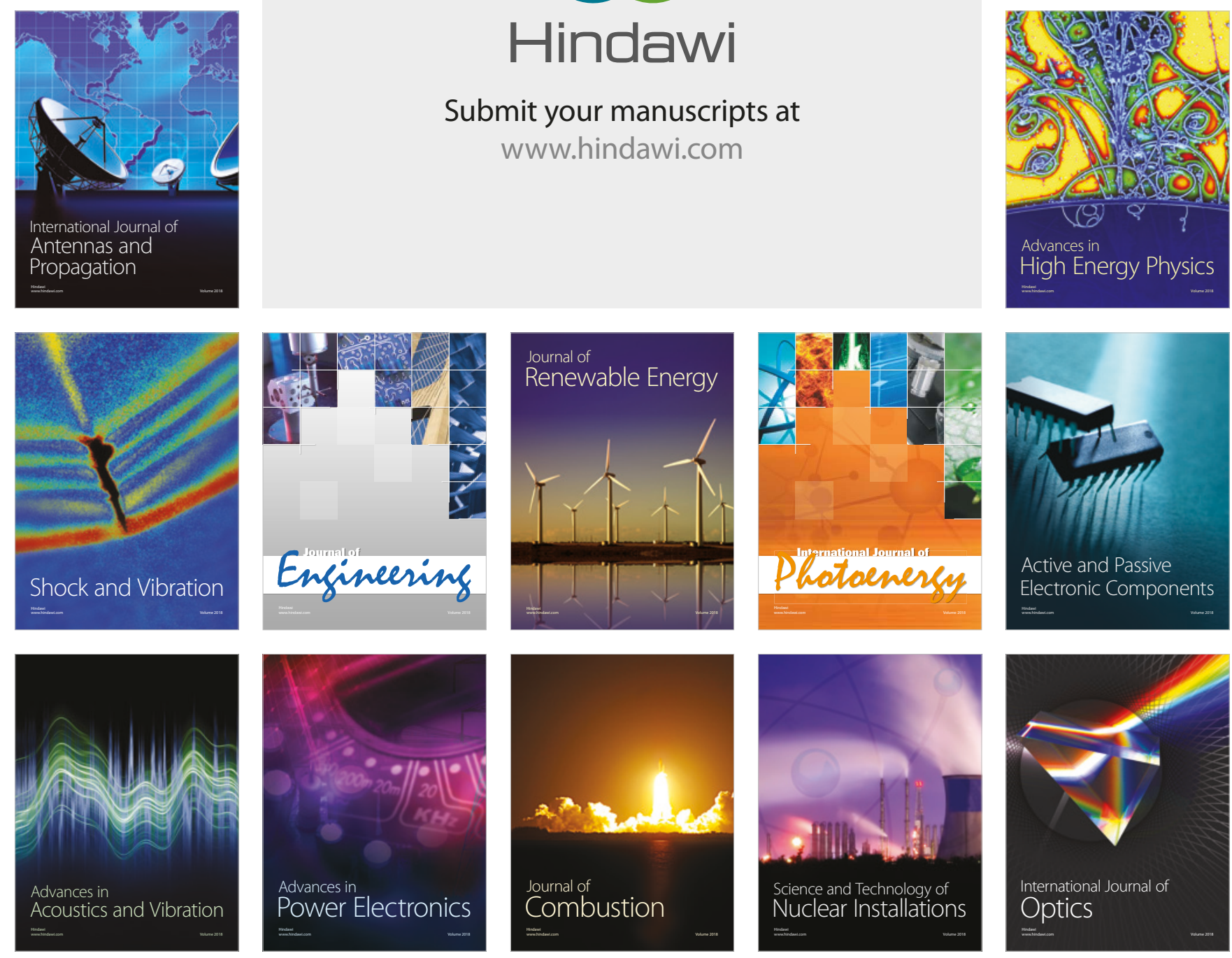